\title{
Special issue: Plasmodesmata
}

\author{
Manfred Heinlein • Alexander Schulz • Karl Oparka
}

Published online: 14 December 2010

(C) Springer-Verlag 2010

This special issue of Protoplasma provides an overview of the current standing of research and knowledge regarding the structure, function, and biological role of plasmodesmata (PD), the small channels through which adjacent plant cells communicate. The idea of creating a special issue on PD was conceived during the international "Plasmodesmata 2010" conference held on March 21-26 in Sydney, Australia. The organization of this meeting was headed by Prof. Robyn Overall (University of Sydney) and brought together researchers studying various aspects of PD structure and regulation, development, virus movement, and macromolecular trafficking. Since the extended network of PD is connected to the vascular phloem for the dissemination of molecules between organs, the meeting also covered aspects of phloem loading and unloading, as well as contributions profiling the composition of phloem exudate. This special issue of Protoplasma combines review articles with original reports describing some of the research presented at the conference. An overview of the conference is given in the introductory article by Jessica Fitzgibbon and Anne Vatén, two PhD students who won prizes for their excellent poster presentations. We hope that the collection of reviews and original articles highlighted in this issue will become an important resource for scientists interested in cell communication and PD-mediated trafficking and that it will attract young researchers to join this exciting and rapidly changing field of research.

\footnotetext{
M. Heinlein $(\square)$

Institut de Biologie Moléculaire des Plantes du CNRS

(UPR 2357), Université de Strasbourg,

12, rue du Général Zimmer,

F-67084 Strasbourg cedex, France

e-mail: manfred.heinlein@ibmp-cnrs.unistra.fr

\section{A. Schulz}

Department of Plant Biology and Biotechnology,

Copenhagen University,

Thorvaldsensvej 40, Frederiksberg C,

DK-1871 Copenhagen, Denmark

e-mail: als@life.ku.dk

K. Oparka

University of Edinburgh,

King's Buildings, Mayfield Rd,

Edinburgh EH9 3JH, UK

e-mail: Karl.Oparka@ed.ac.uk
} 